\title{
Infrared Thermography in Serotonin-Induced Itch Model in Rats
}

\author{
Yousef Jasemian $^{*}, 1$, Parisa Gazerani ${ }^{2}$ and Frederik Dagnaes-Hansen ${ }^{1}$ \\ ${ }^{I}$ Department of Medical Microbiology and Immunology, Aarhus University, Denmark \\ ${ }^{2}$ Center for Sensory-Motor Interaction (SMI), Department of Health science and Technology, Aalborg University, \\ Denmark
}

\begin{abstract}
The study validated the application of infrared thermography in a serotonin-induced itch model in rats since the only available method in animal models of itch is the count of scratching bouts. Twenty four adult Sprague-Dawley male rats were used in 3 experiments: 1) local vasomotor response induced by intradermal serotonin $(10 \mu 1)$ was evaluated against isotonic saline and Methysergide $(10 \mu 1) ; 2)$ dose-temperature relation of intradermal serotonin with different concentrations $(1 \%, 2 \%, 4 \%)$ at the site of injection was tested; 3$)$ the local vasomotor responses in anaesthetized rats with no scratching reflex was investigated. Serotonin elicited significant scratching and lowered the local temperature at the site of injection. A negative dose-temperature relationship of serotonin was found by thermography. Vasoregulation at the site of serotonin injection took place in the absence of scratching reflexes. Thermography is a reliable, non-invasive, and objective method for assessment in serotonin-induced itch model in rat.
\end{abstract}

Keywords: Infrared thermography, rat, serotonin, scratching bouts, vasomotor response.

\section{INTRODUCTION}

Itch is an unpleasant sensation associated with a desire to scratch [1], which can impair the quality of life. It is a frequent complaint and the most common symptom in metabolic and various skin diseases [2, 3]. Scratching behavior is an important component of different skin diseases in human, and the duration of scratching indicates the degree of skin damage [4]. Itch sensation acts as a physiological self-protective mechanism to support the defense of the skin against external damaging agents [3]. Similar mechanism is known from other cutaneous sensations such as pain, touch, vibration, cold and heat. Clinically, itch is classified into four categories: pruritoceptive itch, neuropathic itch, neurogenic itch and psychogenic itch $[5,6]$. The present study will only consider pruritoceptive itch.

Currently available medicines are often not successful in subsiding pruritus and there is still a need for new antipruritic medicine for treating itch in clinical dermatology. New medicines are required by law to be tested on animals (European directive 2001/83/EC, Annex 1 part 4). Scratching behavior is widely used for assessment of itch in animal models [4, 7]. There are a few well-established pharmacological animal models for studying itch and its respective medicine that are mostly based on application of prutitogenic agents into the skin of animal and assessment of scratching behaviors [8-12]. Although scratching behavior is used as an itch index in animal studies, it is also a component of normal grooming [13], thus scratching may occur under non-pruritic conditions. Hence, establishment of

*Address correspondence to this author at the Department of Medical Microbiology and Immunology, Building 1240, Wilhelm Meyers Allé 4, Aarhus University, 8000 Århus C, Denmark; Tel: +45 22567713;

E-mail: yousef@jasemian.com a reliable and quantitative method is important in order to make objective assessments of itch in animal models and test the efficacy of new antipruritic drugs.

It has been shown that induced itch in human skin could influence the local skin temperature (vasomotor responses) [14]. There are some difficulties using the conventional technique of contact measurements [15]. These methods are time consuming and often cause soft-tissue deformation during the measurements. To overcome this problem, optical measurements are presented and replacing the conventional approaches. Optical techniques are non-invasive, and have high speed, high resolution and better precision properties [15]. Infrared imaging, as an optical approach, has been used in many studies within the medicine field, including wound care, sport medicine, forensic medicine, anesthesiology, peripheral vascular diseases and cancer diagnosis [16-18]. In infrared thermography, the released infrared radiation with a wavelength of $0.8-1 \mu \mathrm{m}$ creates the temperature distribution of a body surface [19]. An infrared camera detects and captures the infrared heat energy released from body surface. The captured energy is converted to an energy signal [18], which together with other parameters including emissivity, ambient temperature, the distance of the object from the camera and environment humidity is used to calculate the definite temperature of the skin surface [19]. Blood plays an essential role in heat exchange between the body surface and ambient temperature; therefore, identification of some diseases by thermography is generally associated with changes in blood perfusion at superficial level. Infrared thermo-imaging, which makes a clear representation of skin temperature distribution [20], is a non-invasive technique that can potentially be used for assessment of vasomotor response in animal itch models. 


\section{AIMS AND HYPOTHESIS}

The aim of the present study was to validate the application of infrared (IR) thermography in a serotonininduced itch model in rat. It was hypothesized that, infrared thermography can show:

1. Correlation between itch-related scratching behaviors and changes in vasomotor response.

2. Modulation of vasomotor response due to intradermal injection of serotonin by application of methysergide, which is a non-selective serotonin antagonist.

3. Dose-temperature relation of serotonin at the site of injection.

4. Vasomotor response due to itch-induced serotonin is independent of scratching reflex.

\section{MATERIALS AND METHODS}

The study protocol was approved by the Danish Experimental Animal Inspectorate, and all the procedures were carried out in accordance with the International Association for the Study of Pain (IASP) and Guidelines for the Care and Use of Laboratory Animals. The study included 3 experiments; these are explained as following:

\section{Animal}

In all experiments in the present study Sprague-Dawley rats (age: 52-56 days, sex: male and weighted: 252-257 grams) were used. The rats were housed ( 2 per cage) in a room under controlled temperature $\left(20 \pm 2{ }^{\circ} \mathrm{C}\right)$ and light (lights on 08:00-20:00 h). Food and water were freely available.

\section{Sample Size}

Previous data indicated that a samples size of 8 was enough to record a significant effect of serotonin on scratching compered with saline [21]. Concidering 3Rs law ("reduce", "replace" and "refine"), the sample size 8 was used in the present study.

\section{Shaving Procedure}

To measure a local skin temperature at the site of injection the rats were briefly anesthetized ( $4 \%$ isoflurane) and the fur over the rostral portion of their back was shaved (area of $3 \times 3 \mathrm{~cm}^{2}$ ). In order to avoid skin irritation and any possible false temperature change in the skin caused by shaving machine, the rats were shaved 24 hours prior to the experiments.

\section{Test Agents}

Serotonin Hydrochloride (25 mg 5-HT; Sigma, Denmark) was used as an itch induced agent. Methysergide maleate was used as serotonin antagonist (2 mg; Sigma, Denmark). Sterile physiological saline $(0.9 \% \mathrm{NaCl})$ was used as control. All test agents were injected intra-dermal (ID). The test agents were prepared by the same experienced laboratory technician, and the investigator was blinded to the content of all injections.

\section{Injection Procedure}

For intra-dermal (ID) injections, a custom-made special loose restrainer was used. The restrainer had an opening window $\left(3 \times 3 \mathrm{~cm}^{2}\right)$ with a sliding door on the top. To eliminate any stress factor, for the ID injections the restrainer was placed in the chamber in order for the rat to enter the restrainer on its own will. From the opening on the top of the restrainer the solutions were injected over 20 seconds using a $50-\mu 1$ Hamilton micro syringe through PE-50 micro tube connected to a needle. A silver pen was used to mark the site of injection. The needle was left in place for 10 seconds post injection. Then, the needle was removed and the rat was quickly placed in an opaque, open-top, glass observation chamber ( $\mathrm{L} \times \mathrm{W} \times \mathrm{H}=33 \times 33 \times 40 \mathrm{~cm}^{3}$ ) for IR videorecording.

\section{Local Temperature Measurement}

An infrared video camera (SATIR-S280, GSAT INC., China) was used for continuous real time monitoring of the local skin temperature. The camera has spectral range of 7.5$13 \mu \mathrm{m}$ and measures temperature in the range of $-40^{\circ} \mathrm{C}$ to $+160^{\circ} \mathrm{C}$ with accuracy of $\pm 0.02^{\circ} \mathrm{C}$.

\section{Monitoring Procedure}

Prior to any injection, a 5 minutes baseline thermography was recorded to obtain a baseline temperature at the shaved area. After any injection the rates were continuously IR video recorded in 90 minutes in experiments 1 and 2 . In experiment 3 the IR video recording's time was 45 minutes. Shortly after the injections the investigator left the room to avoid any behavior distraction. Both the recording of scratching behaviors and local temperature measurement were done simultaneously in a totally dark room using the IR camera, as the behaviors were clearly recognized in the IR recordings; thus the synchronization problem was eliminated.

\section{Assessment of Scratching Behavior and Local Skin Temperature}

To see whether thermography can indicate a local skin temperature due to an itch-induced agent a well-known animal model of itch applying serotonin into the skin of rat was used [7, 12, 22-25].

A series of one or more scratching movements by the hind paw that is directed toward the injection site is defined as a scratching bout, which ends when the rat either licks its hind paw or places it back on the floor [7]. In the present study, the total number of scratching bouts was used for assessment of itch-induced behaviors. Playback of the video recordings was slowed down to $1 / 15^{\text {th }}$ of normal speed (15 frames/s resolution) to count the bouts. From the IR images, max., min. and average temperature at the site of injection were extracted and presented as numbers using special software (SatReport 3.1 for SAT camera, China).

Experiment 1: a cross over and double blind experiment was designed. Experiment 1 was conducted by two subexperiments (Exp 1.1 and Exp 1.2).

Exp 1.1: In Exp 1.1 the use of thermography in the above mentioned model was evaluated. The rats were divided into two groups $\left(\mathrm{n}_{1}=\mathrm{n}_{2}=8\right)$, which received either ID serotonin $(10 \mu 1$ of $20 \mathrm{mg} / \mathrm{ml})$ or saline $(10 \mu \mathrm{l}$ of $0.9 \% \mathrm{NaCl})$, and the association between scratching behaviors and temperature at the site of injection in both groups were examined. The $2 \%$ concentration for serotonin was chosen because it elicits the 
greatest number of scratching bouts [26], and it is intermediate compared with concentration of 5-HT used in other studies of rats [12] and mice [23]. Ten micro liters sterile physiological saline $(0.9 \% \mathrm{NaCl})$ was used as control.

Exp 1.2: In order to validate the application of thermography and to see whether thermography can quantitatively show the modulation of local skin temperature caused by serotonin, in Exp 1.2, a well known antagonist for serotonin (Methysergide) was used. One week after the end of the first experiment, the rats were divided into two groups $\left(\mathrm{n}_{1}=\mathrm{n}_{2}=8\right)$, which received either ID serotonin $(10 \mu \mathrm{l}$ of $2 \%)$ plus saline $(10 \mu \mathrm{l}$ of $0.9 \% \mathrm{NaCl})$ or serotonin $(10 \mu \mathrm{l}$ of $2 \%$ ) plus methysergide $(10 \mu \mathrm{l}$ of $0,047 \mathrm{mg} / \mathrm{ml})$ and the number of scratching bouts and local skin temperature changes at the site of injection were assessed. Methysergide injection was prepared at a total concentration of $100 \mathrm{nmol}$ $(47 \mu \mathrm{g} / \mathrm{ml})$ and injected in a volume of $10 \mu \mathrm{l}(10 \mathrm{nmol} ; 0,047$ $\mathrm{mg} / \mathrm{ml})$. Methysergide (0.3-10 nmol) dose-dependently showed to inhibit 5-HT-induced scratching in mice [23].

Experiment 2: In a cross over experiment 8 SpragueDawley male rats were used. This experiment was designed to see if IR thermography can explore a dose-temperature relation between the injected serotonin doses and the corresponding temperature change at the site of injection. The experiment was conducted in a 4 -weeks time span. First week; the rats received ID saline $(10 \mu \mathrm{l}$ of $0.9 \% \mathrm{NaCl})$, which was used as control group. In the next three successive weeks the rats were injected serotonin ID with 3 different concentrations $(10 \mu \mathrm{l}$ of $1 \%, 10 \mu \mathrm{l}$ of $2 \%$ and $10 \mu \mathrm{l}$ of $4 \%$ ). After each injection the relation between temperature change at the site of injection and the injected dose was examined. Injections, shavings and thermography procedures were the same as were explained in experiment 1 .

Experiment 3: Experiment 3 was designed to examine the effect of anesthesia on the change of the local skin temperature due to serotonin injection; avoiding the scratching behavior. The rats were anesthetized with isoflurane $(4 \%)$ for 45 minutes. To keep the rats anesthetized, isoflurane was supplied through a mask. After 5 minutes (in the remaining 40 minutes) the rats were supplied by $2.5 \%$ isoflurane. To maintain the normal body temperature, the rats were placed on an electrical temperature regulator pad. In experiment 3 eight rats were used. To fulfill the 3R-low, the rats were used as their own control. The rats were shaved at two locations; one at the rostral part (treatment area) and the other one at the caudal part of the back (control area). Shaving procedure was the same as described in experiment 1. Experiment 3 contained 2 sub-experiments (Exp 3.1 and $\operatorname{Exp} 3.2)$.

Exp 3.1: In the Exp 3.1 the ID injected agents were $10 \mu \mathrm{l}$ of $2 \%$ serotonin in the treatment area and $10 \mu \mathrm{l}$ of $0.9 \%$ $\mathrm{NaCl}$ saline in the control area.

Exp 3.2: In Exp 3.2 ten $\mu 1$ of $2 \%$ serotonin plus $10 \mu 1$ of $0,047 \mathrm{mg} / \mathrm{ml}$ methysergide were co-administrated ID at the treatment area, and $10 \mu 1$ of $2 \%$ serotonin plus $10 \mu 1$ of $0.9 \%$ $\mathrm{NaCl}$ saline were co-administrated ID at the control area. Prior to any injections, the rats were IR thermography recorded in 5 minutes to obtain a baseline temperature. Then after the injections the rats were monitored for IR thermography in 45 minutes.

\section{STATISTICAL ANALYSIS}

For comparison between the groups every 5 minutes during 45 or 90 minutes either ANOVA or Mann-Whitney rank sum test was used. Either Spearman Rank Order Correlation or Pearson Product Moment was applied to test the correlation between temperature and number of scratching bouts. The significant level was considered as $P<0.05$. Data were presented as Means (S.E.M). The statistics were performed using SigmaPlot version 11.0 program.

\section{RESULTS}

Experiment 1: Experiment 1 contains 2 sub-experiments (Exp 1.1 and Exp 1.2). In Exp1.1, serotonin elicited significant $(p<0.001)$ scratching bouts $(9.281(0.852))$ at the site of injection compared with saline (1.094 (0.852)), and the difference was 8.188 bouts. The temperature at the site of injection in serotonin group (35.607 $\left.(0.0757){ }^{\circ} \mathrm{C}\right)$ was significantly $(p<0.001)$ decreased comparing with saline group $\left(36.050(0.14){ }^{\circ} \mathrm{C}\right)$ and the difference was $0.443{ }^{\circ} \mathrm{C}$. Fig. (1a) illustrates the average temperature at the site of injection, measured every 5 minutes, in saline and serotonin groups. First scratching bouts were observed with approximately 5-10 minutes delay and the successive scratching bouts appeared intermittently lasting up to 90 minutes in almost every rat.

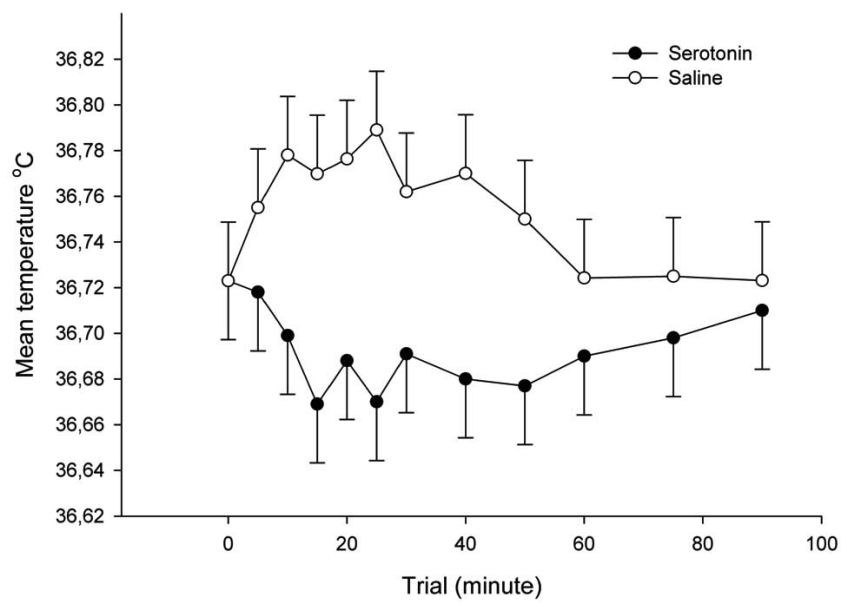

Fig. (1a). Average temperature at the site of injection measured every 5 minutes by infrared thermography in the saline and serotonin groups.

In serotonin group, Spearman Correlation, revealed a significant negative correlation $(\rho=-0.786, \quad p=0.0013)$ between average temperature and the corresponding average number of scratching bouts (Fig. 1b).

In Exp 1.2, serotonin + saline elicited significant $(P<0.001)$ scratching bouts $(9.521(1.004))$ at the site of injection compared with serotonin+methysergide group (1.844 (1.004)) and the difference was 7.677 bouts (Fig. 2a). Temperature at the site of injection in serotonin + saline group $\left(35.138(0.0742){ }^{\circ} \mathrm{C}\right)$ was significantly $(P=0.007)$ reduced compared with serotonin+methysergide group (35.426 $\left.(0.143){ }^{\circ} \mathrm{C}\right)$ and the difference was $0.2880{ }^{\circ} \mathrm{C}$. Methysergide significantly reduced the pruritic effect of serotonin (Fig. 2a) and increased the temperature at the site of injection (Fig. 2b). 


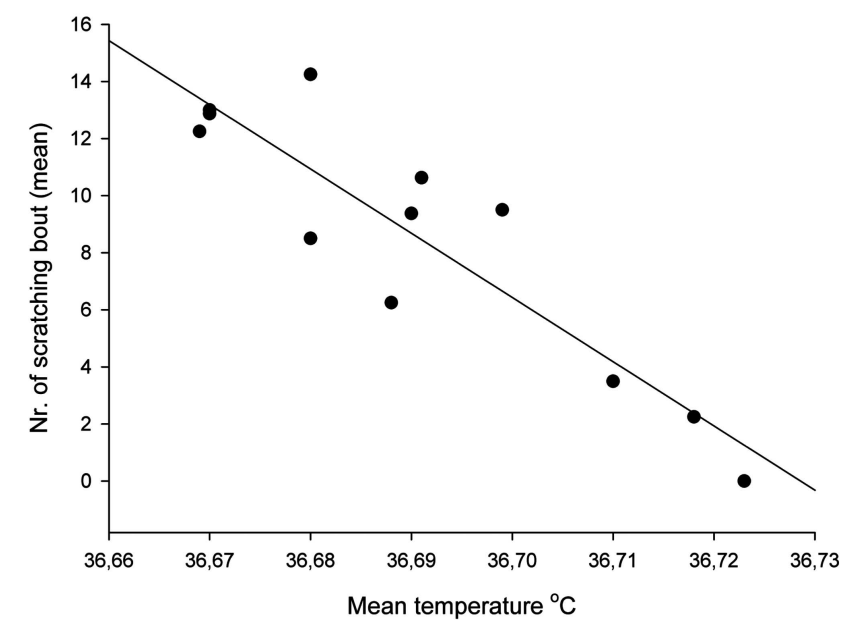

Fig. (1b). Spearman Correlation shows a significant negative correlation $(=-0.786, p=0.0013)$ between average temperature and the corresponding average number of scratching bouts in serotonin group.

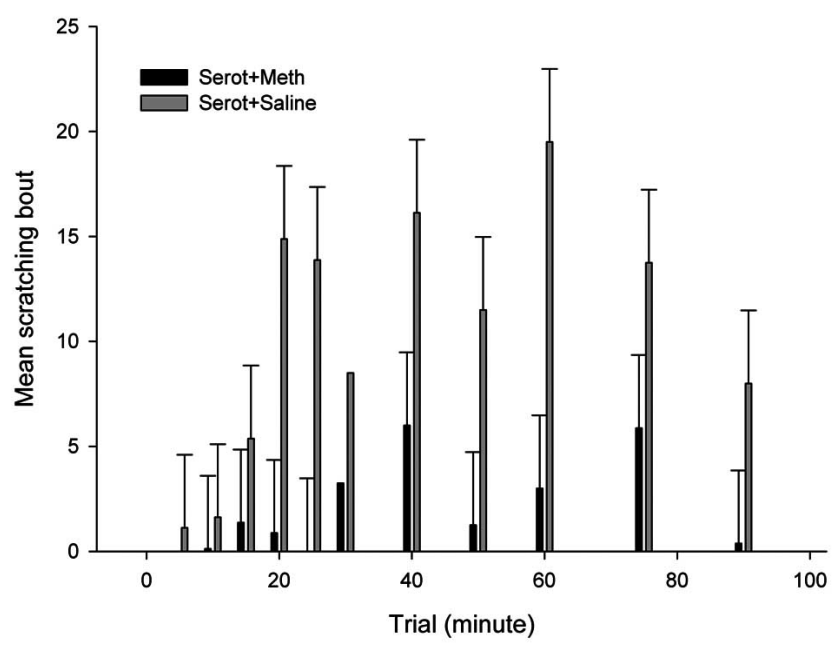

Fig. (2a). Average scratching bouts in serotonin + methysergide and serotonin + saline groups. Methysergide significantly reduced the pruritic effect of serotonin at the site of injection

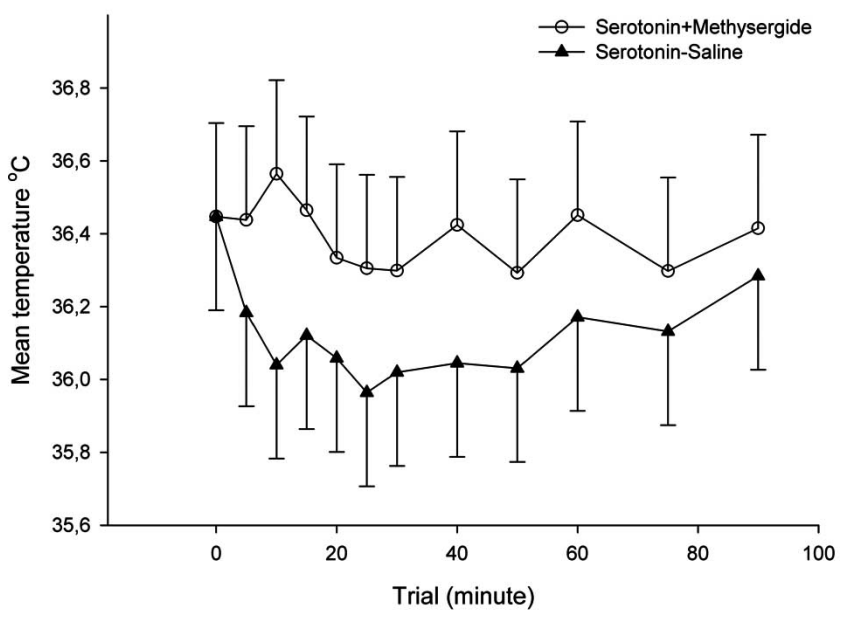

Fig. (2b). Average temperature at the site of injection in serotonin + saline and serotonin + methysergide groups measured every 5 minutes. Serotonin + saline group significantly $(P=0.007)$ reduced vasomotor response (lower temperature) at the site of injection.
Experiment 2: IR thermography could clearly indicate a negative relation (Fig. 3) between the concentrations of the injected serotonin and the corresponding temperature at the site of injection. There were significant differences $(P<0.001)$ when comparing saline group with serotonin groups (1\%,2\% and 4\% concentrations), see Table 1 .

Experiment 3: Comparing the mean temperature at the site of injection in serotonin group with saline group, there was a significant difference $\left(0.687{ }^{\circ} \mathrm{C}, p<0.001\right)$. The most significant difference appeared on the $10^{\text {th }}$ minute of the trials $\left(0.740{ }^{\circ} \mathrm{C}, p<0.001\right)$. The difference was gradually reduced afterwards (Fig. 4a).

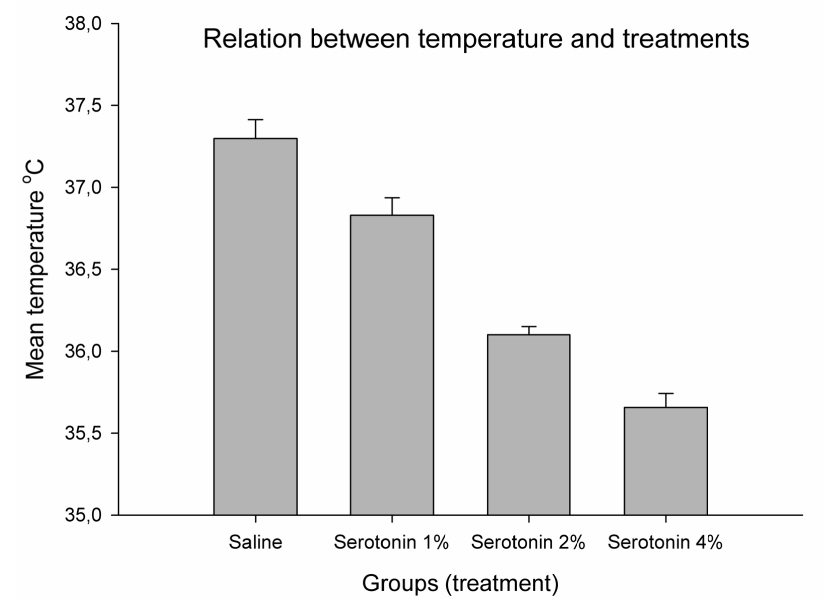

Fig. (3). Dose-temperature relationship of serotonin with different concentrations $(1 \%, 2 \%$ and $4 \%)$, and the corresponding temperature at the site of injection.

Table 1. Dose-Response Effect of Serotonin $(1 \%, 2 \%$ and 4\%) on Vasomotor Response at the Site of Injection, Injected Intradermally

\begin{tabular}{|c|c|}
\hline Comparison & Diff. of Means $\left({ }^{\circ} \mathbf{C}\right)$ \\
\hline \hline Saline $v s$ 1\% Serotonin & 0.469 \\
\hline Saline $v s$ 2\% Serotonin & 1.198 \\
\hline Saline $v s 4 \%$ Serotonin & 1.640 \\
\hline
\end{tabular}

There is a negative association between the concentrations of the injected serotonin and the corresponding temperature at the site of injection. There are significant differences $(P<0.001)$ when comparing saline and serotonin with different concentrations.

Serotonin + methysergide group induced significantly $(p<0.001)$ higher temperature change compared to serotonin + saline group (difference of means: $0.592{ }^{\circ} \mathrm{C}$ ). The most significant difference was observed on the $15^{\text {th }}$ minute of the trials $\left(0.657^{\circ} \mathrm{C}, p<0.001\right)$. Fig. (4b) illustrates that.

\section{DISCUSSION}

To the best of our knowledge, for the first time, we used a combination of thermography method with scratching behavioral assessment in a rat model of itch. The effect of serotonin and methysergide (an antagonist of 5-HT receptor) on scratching behavior and local skin temperature indicated that, there is a correlation between itch-related scratching behaviors and changes in vasomotor response. Methysergide, which is a non-selective serotonin antagonist, modulated the local 
vasomotor response at the site of injection. By IR thermography we could clearly observe a dose-temperature relationship for serotonin on temperature change at the site of injection. Anesthesia showed no influence on vasomotor responses while scratching reflexes were absent.

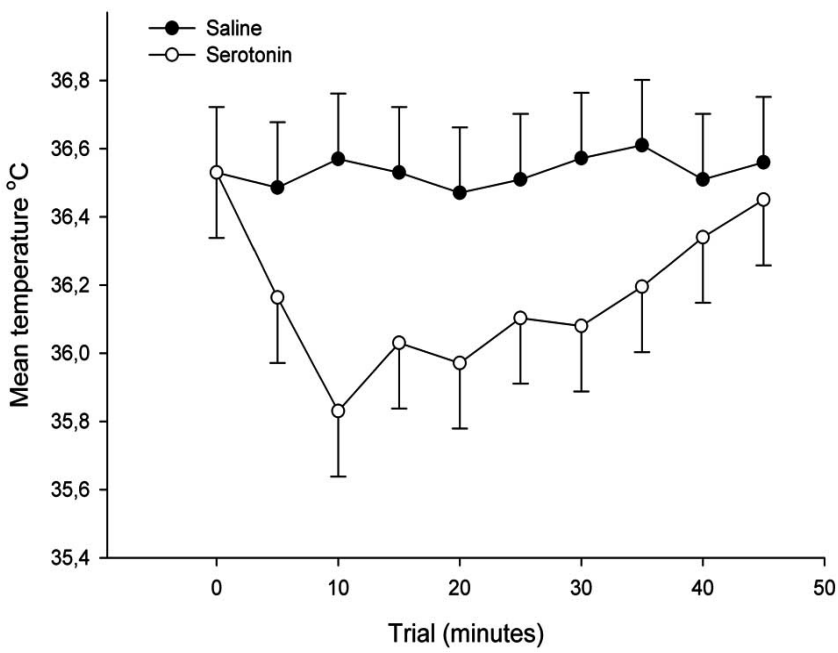

Fig. (4a). Mean temperature at the site of injection in serotonin and saline groups, measured every 5 minutes in 90 minutes. There is a significant $(p<0.001)$ difference.

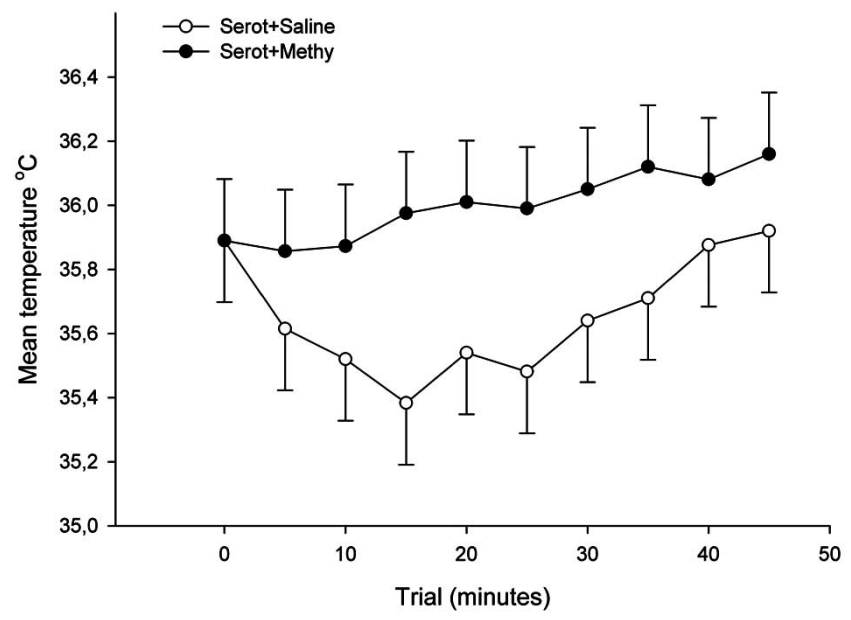

Fig. (4b). Mean temperature at the site of injection in Serotonin + methysergide and serotonin + saline groups, measured every 5 minutes in 90 minutes. There is a significant $(p<0.001)$ difference.

Our findings in the first experiment showed that coadministration of methysergide and serotonin diminished the scratching behavior and increased the skin temperature while co-administration of serotonin and saline, elicited remarkable scratching and decreased the temperature at the site of injection. We observed that the scratching reflexes occurred when the local temperature was low, and was increased after scratching. There was a negative correlation between temperature changes and the number of scratching bouts in serotonin group. A possible explanation for the reduction of the local temperature is that, serotonin might cause local vasoconstriction. This phenomenon was supported by the oposite relation between the concentration of injected serotonin and the temperature at the site injection found in experiment 2.
At the same time serotonin stimulates local cutaneous itchspecific high dense mechano-insensitive neurons using itchspecific high dense innervated C-fibers in the skin (60-70\% of primary afferent neurons that innervate the skin) as afferent units for mediating itch sensations to Central Nerve System (CNS) [27], which leads to the scratching reflexes. Scratching in turn would up-regulate the local blood circulation to wash the stimulating agent away. The washout actions by the blood have been generated in a dynamic manner. This is probably why the changes in temperature at the site of injection found in the present study had waveform. Thomsen et al., believed that "the scratching of the rostral back was due to a local stimulus from the injected skin area, and was not a response to systemic absorption of serotonin into the blood stream" [12]. This statement is in harmony with our results and the above explanation.

When the rats were anesthetized and scratching reflex was absent, the local vasoregulation and blood stream was still taking place. Our results from experiments 1 and 3 indicate that scratching reflex might have an intensifying effect on the local vasoregulation and blood stream. A 5-10 minutes delay in the onset of first scratching reflexes was observed in some rats. This silent period could probably be due to the transient neuronal disturbance resulting from a local injection trauma or a defensive reaction of the animal [12]. Yamaguchi et al. reported a dose-dependent $(0.3-10 \mathrm{nmol})$ inhibition of 5-HT-inducedscratching by methysergide in mice [23]. The used dose for methysergide in the present study was $10 \mathrm{nmol}(0.047 \mathrm{mg} / \mathrm{ml})$, which also showed a significant inhibition of serotonin in the present itch-model in rats. Our result is consistent with the result from Yamaguchi et al. study.

Kosteletzky et al. [28] studied the quality and intensity of the sensations, axon reflex flare, sympathetic skin vasoconstrictions and the interference of scratching in humans. They used histamine and Cowhage which contains 5hydroxytryptamine (serotonin 5-HT) as two different itch stimulators. The results indicated that Cowhage induced a sharper itch sensation and stronger vasoconstrictor reflexes compared with histamine. This finding also supports the results in the present study. Newman et al. investigated in a study the vascular and metabolic effects of serotonin and norepinephrine using the constant-flow perfused rat hindlimb model. They observed a transient washout of red blood cells when low-dose norepinephrine (LDNE) was added to the perfusion solution. However, they did not observe red cell washout when serotonin was added to the perfusate. The result of Newman et al. study indicates that, LDNE employs a new vascular space and serotonin close off the formerly perfused vascular space. Based on these findings, Newman et al. concluded that serotonin increases functional shunting and decreases capillary surface area. Newman et al. found that serotonin in the course of its vasoconstrictor activity at selected sites in the rat hindlimb vasculature inhibit access to nutritional regions and increases flow in nonnutritive vessels. The concept of serotonin affects on functional vascular shunting was earlier proposed by Rippe et al. [29]. Rippe et al. observed that serotonin infusion decreased both capillary diffusion and filtration capabilities in the rat hindlimb model. Results from Rippe et al. and Newman et al. support our finding regarding the vasoconstriction effect of serotonin. 
On the other hand, Zhang et al. [30] investigated the role of serotonin in controlling blood flow and protein kinetics in both normal skin and scalded skin, using methysergide to block the action of serotonin on protein kinetics in normal and scalded skin of anesthetized rabbits. They reported that methysergide administration reduced blood flow in normal and scalded skin, indicating the primary role of serotonin in increasing wound blood flow (vasodilatation). This finding is not in agreement with our results. One possible explanation could be that Zhang et al. administered methysergide through intravenous infusion and afterwards was injected intramuscularly every $3-5 \mathrm{~h}$ until the 48th $\mathrm{h}$, while we administrated serotonin and methysergide intradermal and studied the effect of serotonin locally where methysergide challenging serotonin directly at the site of injection and avoiding the systemic effect. We know that these two vascular routes (nutritive and non-nutritive) are controlled by a variety of vasoregulators (e.g. hormones, neural input, insulin, etc.)[31], in which each and every has different underlying vasoregulation mechanisms. Thus, these fundamental differences make it impossible to compare our results with those results from Zhang et al.

\section{CONCLUSION}

Findings from the present study indicate that, there is a significant negative correlation between average temperature and average number of scratching bouts in serotonin group. Serotonin+saline group decreased the temperature compared with serotonin+methysergide group. Our results also showed that serotonin has a vasoconstriction effect, and local vasoregulation at the site of injection is independent of scratching reflex; however, scratching reflexes intensify the local vasoregulation effect of serotonin. Outcomes of the present study suggest that, assessing anti-pruritus drugs is possible in anesthetized animal reducing unpleasant itch experience in animals. Furthermore, handling and assessment of quantitative measurements are easier when the animals are anesthetized.

Application of IR thermography in serotonin-evoked itch model in rats proved to be a useful objective, non-invasive method to monitor dynamic real time changes in pruritus and anti-pruritus testing in dermatology research. Moreover, this method would be useful for monitoring of medications and treatments in clinical dermatology.

\section{CONFLICT OF INTEREST}

The authors state no conflict of interest

\section{ACKNOWLEDGMENTS}

We would like to thank Mie Aarup for her assistance in drug preparation.

\section{REFERENCES}

[1] Savin JA. How should we define itching? J Am Acad Dermatol 1998; 39(2 Pt 1): 268-9.

[2] Greaves MW, Wall PD. Pathophysiology of itching. Lancet 1996 ; 348(9032): 938-40.

[3] Stander S, Steinhoff M, Schmelz M, Weisshaar E, Metze D, Luger T. Neurophysiology of Pruritus: Cutaneous Elicitation of Itch. Arch Dermatol 2003; 139(11): 1463-70.

[4] Orito K, Chida Y, Fujisawa C, Arkwright PD, Matsuda H. A new analytical system for quantification scratching behaviour in mice. $\mathrm{Br} \mathbf{J}$ Dermatol 2004; 150(1): 33-8.

[5] Schmelz M. A neural pathway for itch. Nat Neurosci 2001; 4(1): 9-10.
[6] Yosipovitch G, Greaves MW, Schmelz M. Itch. Lancet 2003; 361(9358): 690-4.

[7] Nojima H, Carstens E. Quantitative assessment of directed hind limb scratching behavior as a rodent itch model. J Neurosci Methods 2003; 126(2): 137-43.

[8] Laidlaw A, Flecknell P, Rees JL. Production of acute and chronic itch with histamine and contact sensitizers in the mouse and guinea pig. Exp Dermatol 2002; 11(4): 285-91.

[9] Ueda Y, Inoue T, Rahman MA, Yatsuzuka R, Jiang S, Kamei C. A new chronic itch model accompanied by skin lesions in hairless mice. Int Immunopharmacol 2006;6(10): 1609-15.

[10] Kuraishi Y, Nagasawa T, Hayashi K, Satoh M. Scratching behavior induced by pruritogenic but not algesiogenic agents in mice. Eur $\mathrm{J}$ Pharmacol $1995 ; 275(3)$ : 229-33.

[11] Sugimoto Y, Nakamura Y, Hossen MA, Watanabe T, Kamei C. Evaluation of the effects of anti-pruritic drugs on scratch responses using histamine H1 receptor-deficient mice. Eur J Pharmacol 2003; 470(1-2): 113-6.

[12] Thomsen JS, Petersen MB, Benfeldt E, Jensen SB, Serup J. Scratch induction in the rat by intradermal serotonin: a model for pruritus. Acta Derm Venereol 2001; 81(4): 250-4.

[13] Aldridge JW. Grooming. In: Whishaw IQ, Kolb B, editors. The behavior of the laboratory rat Oxford, New York: Oxford University press 2005.

[14] Weisshaar E, Ziethen B, Gollnick H. Can a serotonin type 3 (5-HT3) receptor antagonist reduce experimentally-induced itch? Inflamm Res 1997; 46(10): 412-6.

[15] Cheng VS, Bai J, Chen Y. A high-resolution three-dimensional farinfrared thermal and true-color imaging system for medical applications. Med Eng Phys 2009; 31(9): 1173-81.

[16] Jiang LJ, Ng EY, Yeo AC, et al. A perspective on medical infrared imaging. J Med Eng Technol 2005; 29(6): 257-67.

[17] Ebata T, Aizawa H, Kamide R, Niimura M. The characteristics of nocturnal scratching in adults with atopic dermatitis. Br J Dermatol 1999; 141(1): 82-6.

[18] Kennedy DA, Lee T, Seely D. A Comparative Review of Thermography as a Breast Cancer Screening Technique. Integr Cancer Ther 2009; 8(1): 9-16.

[19] Diakides NA, Bronzino JD. Medical Infrared Imaging. Boca Raton, FL:. CRC Press 2008.

[20] Diakides NA. Advances in medical infrared imaging. IEEE Eng Med Biol Mag 2002; 21(6): 32-3.

[21] Nojima H, Carstens E. 5-Hydroxytryptamine (5-HT)2 receptor involvement in acute 5-HT-evoked scratching but not in allergic pruritus induced by dinitrofluorobenzene in rats. J Pharmacol Exp Ther 2003; 306(1): 245-52.

[22] Akiyama T, Merrill AW, Zanotto K, Carstens MI, Carstens E. Scratching behavior and Fos expression in superficial dorsal horn elicited by protease-activated receptor agonists and other itch mediators in mice. J Pharmacol Exp Ther 2009; 329(3): 945-51.

[23] Yamaguchi T, Nagasawa T, Satoh M, Kuraishi Y. Itch-associated response induced by intradermal serotonin through 5-HT2 receptors in mice. Neurosci Res 1999; 35(2): 77-83.

[24] Nojima H, Simons CT, Cuellar JM, Carstens MI, Moore JA, Carstens E. Opioid modulation of scratching and spinal c-fos expression evoked by intradermal serotonin. J Neurosci 2003; 23(34): 10784-90.

[25] Cuellar JM, Jinks SL, Simons CT, Carstens E. Deletion of the preprotachykinin A gene in mice does not reduce scratching behavior elicited by intradermal serotonin. Neurosci Lett 2003; 339(1): 72-6.

[26] Jinks SL, Carstens E. Responses of superficial dorsal horn neurons to intradermal serotonin and other irritants: comparison with scratching behavior. J Neurophysiol 2002; 87(3): 1280-9.

[27] Schmelz M, Schmidt R, Bickel A, Handwerker HO, Torebjork HE. Specific C-Receptors for Itch in Human Skin. J Neurosci 1997; 17(20): 8003-8.

[28] Kosteletzky F, Namer B, Forster C, Handwerker HO. Impact of scratching on itch and sympathetic reflexes induced by cowhage (Mucuna pruriens) and histamine. Acta Derm Venereol 2009; 89(3): 271-7.

[29] Rippe B, Folkow B. Simultaneous measurements of capillary filtration and diffusion capacities during graded infusions of noradrenaline (NA) and 5-hydroxytryptamine (5-HT) into the rat hindquarter vascular bed. Acta Physiol Scand 1980; 109(3): 265-73.

[30] Zhang XJ, Irtun O, Zheng Y, Wolfe RR. Methysergide reduces nonnutritive blood flow in normal and scalded skin. Am J Physiol Endocrinol Metab 2000; 278(3): E452-61. 
[31] Clark MG, Rattigan S, Clerk LH, et al. Nutritive and non-nutritive blood flow: rest and exercise. Acta Physiologica Scandinavica 2000;

168(4): 519-30.

Received: February 2, 2011

Revised: May 31, 2011

Accepted: June 6, 2011

(C) Jasemian et al.; Licensee Bentham Open.

This is an open access article licensed under the terms of the Creative Commons Attribution Non-Commercial License (http: //creativecommons.org/licenses/by$\mathrm{nc} / 3.0 /$ ) which permits unrestricted, non-commercial use, distribution and reproduction in any medium, provided the work is properly cited. 